\title{
Strategic Professional Development for Busy Teachers: Profile of a High-Impact Instructional Design
}

\author{
Sarah Bryans-Bongey \\ University of Northern Iowa \\ Cedar Falls, Iowa \\ Craig Rosen \\ Desert Research Institute \\ Las Vegas, Nevada
}

\begin{abstract}
This NASA-funded professional development project offered Nevada middle school and high school teachers training to support the use of unmanned aircraft systems (UAS) in the secondary STEM curriculum. The project took place during the academic school year and - due to time constraints among teacher-participants - challenged organizers to design a professional development experience that would provide essential preliminary safety information and encourage participant-collaboration while making the most of a limited number of hours available for in-person training. In an effort to extend the benefits of the project, teachers completing the training took part in a lesson planning competition, leading to prizes and publication of the top UAS/STEM lesson plans. The training provided opportunities for teachers to master essential safety information, connect with one another, explore flight simulation activities, fly drones, plan lessons, and deliver new curriculum and experiences to students in middle and high school settings. The design of the project was unique in its inclusion of strategic design elements that ranged from an online course site with FAA/safety content and quiz to a keynote/dinner presentation, handson workshops, a lesson plan competition, webinars, and a circulating curriculum kit that provided lesson plans and instructional materials to secondary STEM teachers requesting the kit. With limited funds and a total of ten hours of in-person instructional time, this thoughtfully constructed training leveraged online resources, received high ratings from participating teachers, and exceeded its goal of reaching over 1000 students at the middle school and high school level.
\end{abstract}

Keywords: blended format; instructional design; teacher; professional development; STEM. 


\section{Introduction}

For teacher preparation programs and secondary schools concerned with the instruction of students in grades 7-12, a NV NASA grant-funded project set out to promote student interest in STEM through a project designed to help teachers incorporate UAS in the development of lesson plans and learning experiences associated with STEM curriculum.

Objectives were to: (1) train participating K-12 teachers to develop and implement STEM curriculum through expert training and hands-on experiences with UAS and (2) foster exposure/interest in STEM by reaching over 1000 students with UAS/STEM concepts, content, and activities.

The project sought to benefit teachers and students state-wide, yet project organizers were challenged to address the busy schedules and often-remote locations of targeted participants. To address these needs, a range of instructional approaches was adopted. The outcome of the training was highly successful both in terms of teacher-evaluations and in the sheer number of schools and students served. This paper describes results as well as the various instructional design components that were key to the project's success.

Teachers of grades 7-12 STEM content were recruited to participate in a professional development experience in which they were taught about drones and developed ideas on how they might be used as a mechanism to excite student interest in various subject areas including computer science, mathematics, physics, and biology as well as aviation and engineering. Presentations by UAS professionals, lesson planning support, and hands-on exposure to a flight simulation lab, the use of programmable drones, and flight practice with a licensed pilot were popular aspects of this experience.

Objectives of the project as well as a larger emphasis on STEM are consistent with ongoing efforts to diversity Nevada's economy. Goal 7 of the Nevada Science and Technology plan in transportation emphasizes the need to "expand the UAS industry... and provide the necessary workforce" (GOED, 2012, p.9). This includes specific strategies to (1) provide research and development using unmanned aerial systems that will help attract industry to the state and (2) develop education programs in UAS that will support economic development (NSHE, 2015, p. 26). Additionally, the plan to facilitate the teaching of STEM with UAS aligns with Nevada's state plan to stimulate innovation in core and emerging industries and to increase opportunity through education and workforce development. As a result, this project sought to incorporate UAS in the STEM curriculum while also meeting criteria outlined in NASA's strategic plan (National Aeronautics and Space Administration, 2016).

By supporting and training 26 secondary teachers, the benefits of this professional development effort went on to reach the many middle and high school students taught by those teachers. Elements of the project also included the creation and sharing of UAS lesson plans and the development and circulation of a curriculum kit (known as a 'Green Box') that the Desert Research Institute (DRI, 2016) developed to provide UAS and lesson resources to teachers 
who were not involved in the initial training project. This circulating curriculum kit was field tested by one of the project leaders in the context of his middle school classroom. It includes lesson plans generated by the teacher-participants, as well as all needed materials for implementation.

Research components of this project addressed the value of incorporating UAS in STEM instruction and explored the impact of a multifaceted and hybrid form of professional development and outreach. Data was collected through pre- and post- surveys that were completed by teachers at the time they applied to participate in the training and again three weeks after the submission of lesson plans and a lesson plan competition.

The use of UAS as a gateway for teaching students STEM content is an emerging approach. In addition to building upon the student-engagement and educational benefits described in the literature, the outcome of this project was highly effective through its unique and hard-working instructional design. Figure 1.0 represents a schematic of a hybrid project design involving online and $\mathrm{f} 2 \mathrm{f}$ training as well as results that include the creation of professionally-edited lesson plans and the generation of a curriculum kit housed by the Desert Research Institute for circulation to middle schools across the state. Research associated with this case study includes results from pre- and post-surveys completed by teachers participating in this project as well as data collected by the Desert Research Institute based on the design and circulation of a UAS/STEM Green Box or Curriculum Kit. Within the parameters of 10 face-toface instructional hours, the hybrid design and extensions led to specific increases in teacher-use of UAS in the classroom and a significant impact based on first-hand reports from participating teachers.

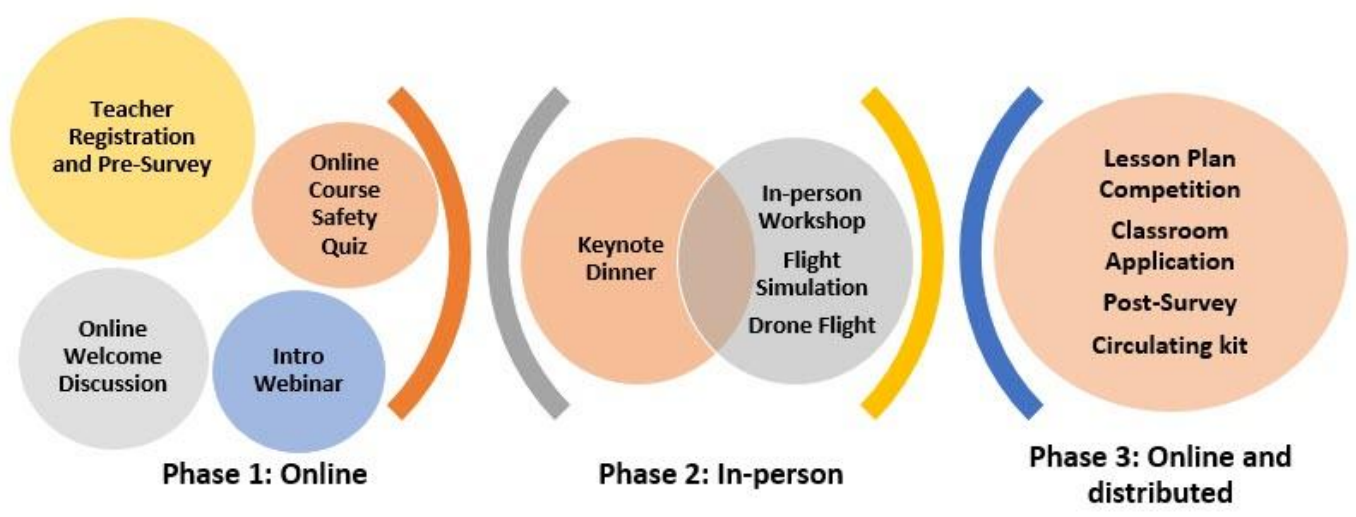

Figure 1: Schematic diagram depicting three phases of the PD project design

\section{Literature Review}

According to a recent study and report on the future occupations, workforce needs are changing and "while some jobs are threatened by redundancy and others grow rapidly, existing jobs are also going through a change in the skill sets required to do them" (World Economic Forum, 2016, p.3). There is an increasing emphasis on the need for schools and teachers to provide curricular 
content that will prepare K-12 students for the workforce of the future. This is in addition to many standards-based outcomes that schools and teachers must consider when developing and presenting instructional content and experiences. During the school year, teachers are often eager to incorporate innovative and engaging content relating to robotics and unmanned aircraft systems, however, factors that limit their participation in professional development experiences often include constraints of time, funding, and other resources.

The incorporation of drones in the curriculum is not new. However, required training presented some challenges due to the need for practical and hands-on approaches as well as foundational information relating to legal issues, history, privacy and best practices. Fishman, Konstantopoulos, Kubitskey, Vath, Park, Johnson, and Edelson (2013) conducted research to determine the value of online versus face-to-face approaches in professional development. They concluded that both formats have merit. Researchers argue online programming makes it easier to conduct the training during the school year and allows participating teachers to work at their own pace, make use of small chunks of time, and review online PD content on an as needed basis. Meanwhile, benefits of face-toface PD seems include opportunities for greater collegiality and sharing of information among teachers (Fishman, et al., 2013). This grant-funded professional development project adopted both online and face-to-face approaches in an effort to conduct the project during the standard academic year and make the most of teacher time and training resources.

In planning the project, the technological aspects and demands of the training added complexity to the instructional planning and design. The grant proposal itself, with its clear establishment and articulation of desired outcomes and measures of success emphasized the importance of planning consistent with the idea of beginning with the end in mind (Wiggins and McTighe, 2008). Additionally, professional development experts suggest that various modalities such as learning management systems, web pages, and other online or asynchronous approaches are sometimes favoured approaches among faculty and others with full schedules who may not be able to attend in-person workshops (Kuhlenschmidt, 2010). This project design made use of such approaches to extend and enrich instructional opportunities and experience, with the inclusion of additional face-to-face events being an essential element. In the 2017 Horizon Report on technology in higher education, the New Media Consortium discusses "cultures of innovation." The report lists a Drone Challenge Project conducted by James Madison University (JMU) as a project that exemplifies a move away from traditional approaches and toward higher education acting as an incubator for design solutions that meet 'real world' challenges. The intent of the Drone Challenge "is to determine innovative solutions to complex global problems (Adams Becker, Cummins, Davis, Freeman, Hall Giesinger, \& Ananthanarayanan, 2017, p. 10). Another example described in the literature took place at an Australian University and involved the use of drones in the teaching of geography. The intent was to "engage students in the learning of geographical skills as well as allowing them to collect their own data and make observations" (Smith, Sefton, \& Chaffer, 2015, p. 25). Based on feedback from students involved in this project, using the drone for 
data collection and mapping was helpful in various ways, including helping students develop an understanding of scale.

This project built upon the idea of engaging STEM students using UAS and - in so doing - implemented a high impact instructional design that extended the reach to over 3000 students and 20 schools. Similar to the use of UAS in higher education described by Adams Becker et al. (2017), teachers at the kindergarten through 12th (K-12) grade level are using drones to teach at the K-12 level (Carnahan, Crowley, Hummel, \& Sheehy, 2016; Fokides, Papadakis, \& KourtisKazoullis, 2017; Levy, 2015). Schools have also begun incorporating UAS clubs in their after-school offerings, and UASs are being used to promote engagement and learning in a variety of subject areas, not just aviation. Fokides, et al. conducted a quasi-experimental study in which students were taught metric measurements using drone flight. The study underscored the value of equipping K-12 teachers to incorporate drones through its findings that student attitudes toward the use of UAS were 'highly positive' and that students using drones to explore metric measurement outperformed peers in the control group in some areas.

In an article on advancing STEM education, Moore and Smith emphasize the importance of professional development, stating, "teachers and administrators need professional learning experiences that prepare them to work within and develop STEM integration learning environments for K-12 students" (Moore \& Smith, 2014, p. 7). A study by Boitshwarelo (2009) endorsed the value of blended learning for providing professional development to science teachers. In an article describing workshops involving a hybrid and flipped instructional design, researchers explored the benefits of a workshop designed to help educators address unfamiliar concepts and discomfort with using unfamiliar technology in an academic setting (Kehoe, Schofield, Branigan, \& Wilmore, 2018). Similar to the findings of Kehoe, et al., the current study found a specialized instructional design was highly effective in meeting the challenges of incorporating high tech devices such as unmanned aircraft systems in professional development. Through the provision of online content relating to essential safety information and an associated online quiz, the blended format made it possible to prepare participants for the face-to-face workshop and establish collaborative support systems and access to expert consultants prior to hands-on use of the drones themselves (Bryans-Bongey, 2018).

In an effort to promote STEM education while at the same time address complex challenges, this Nevada NASA Space Grant project was unique in its emphasis on professional development for Nevada K-12 teachers. The project offered training and support for middle school and high school teachers to develop expertise and lesson plans featuring the use of UAS to inspire student interest in various areas of STEM. Specific lesson plans incorporated the use of drones to teach STEM subjects. For example, specific subject areas and lesson plans included: Physics (Newton's Law), Biology (Bird Flight Benefitting Man), and Engineering (UAS Delivery Design challenges). 
Books and resources are increasingly available to assist teachers in their early efforts to include the excitement of UAS or drones in the curriculum. For example, the SOAR model seeks to establish school and teacher guidelines relating to safety, operations, active learning, and research in the use of UAS in education (Carnahan, et al., 2016). Additionally, emerging articles from around the world indicate that drones have the potential to teach STEM content to K-12 students, including those at the primary level (Fokides, et al., 2017).

The rapid advancement of robotics, computer technology, and UAS as potential areas of economic development is an area of interest for workforce development and economic diversification in the state of Nevada. Tapping the power of UAS and specifically drones to teach STEM continues to be a specific area of exploration described at a recent Nevada State-wide NASA EPSCoR and Space Grant Meeting (Bryans-Bongey, 2017). However, the complexity of the topic, the need to disseminate safety and privacy information prior to the $\mathrm{f} 2 \mathrm{f}$ training, and the short time frame for in-person events requires the design of a multi-phased professional development experience.

\section{Methods}

With the goal being to foster a diverse and capable NV STEM workforce using UAS in the secondary school curriculum, our project was designed with specific inputs and objectives in mind and extended the two-day training experience through the use of an online course and several webinars. Teachers were recruited through the Nevada State Science Teachers Association, through mailing lists and professional development newsletters maintained by the Desert Research Institute, and by regional school districts. Thirty-four teachers registered, and 26 went on to participate in the training. Twenty-one of the 26 participating teachers completed the follow-up survey.

The project collected both quantitative and qualitative data through various means, including Learning Management System (LMS) tracking data, participation numbers, the success of participants in developing lesson plans and a curriculum kit, and pre- and post- survey data from participating teachers.

Once admitted to the program, the hybrid design of this training ensured that teacher-participants gained a good foundational understanding of privacy issues and safety rules relating to UAS usage (Federal Aviation Administration, 2019). Lesson plans and post-lesson notes by teacher-participants were also collected through the LMS hosted by Nevada State College.

The online learning management system assisted with the tracking of quiz completion rates and scores. Participating teachers were required to complete all aspects of the training to receive continuing education credits. However, the survey as well as other data indicated that receipt of professional development credit was not a motivating factor behind teacher participation in the project. Follow up surveys allowed us to verify the number of students taught based on the teacher training provided and also measured teacher satisfaction with the training itself. Such a concurrent mixed-methods approach was possible based 
on the inclusion of a qualitative thread of inquiry within a brief and primarily quantitative survey (Creswell, 2013).

Table 1. Describes the project based on goals, interventions, and results.

Table 1

Project Design including Goals, Interventions, and Results

\begin{tabular}{|l|l|l|}
\hline Goal & Interventions & Results \\
\hline $\begin{array}{l}\text { Prepare 25-30 K-12 } \\
\text { teachers to develop and } \\
\text { implement STEM } \\
\text { curriculum through } \\
\text { expert training and } \\
\text { hands-on experiences } \\
\text { with UAS }\end{array}$ & $\begin{array}{l}\text { Provide participating secondary } \\
\text { teachers with Pre- and Post- } \\
\text { Orientation, Training, and } \\
\text { Support through access to a } \\
\text { password-protected site in the } \\
\text { Learning Management System } \\
\text { (LMS) }\end{array}$ & $\begin{array}{l}\text { Online/LMS usage reports } \\
\text { verified teacher participation. } \\
\text { Based on provided content and } \\
\text { quiz results in the LMS, all of the } \\
\text { 26 teachers participating in the } \\
\text { workshop obtained needed } \\
\text { foundational information as } \\
\text { demonstrated by their passing } \\
\text { the preliminary online exam } \\
\text { with 100\% accuracy. }\end{array}$ \\
$\begin{array}{l}\text { Face-to-face elements: Keynote } \\
\text { on Drones: Past, Present, and } \\
\text { Future, and Overview Dinner at } \\
\text { Desert Research Institute (DRI) }\end{array}$ & $\begin{array}{l}\text { Teachers participate in full day } \\
\text { hands-on STEM/UAS Institute } \\
\text { at Nevada State College (NSC). }\end{array}$ & $\begin{array}{l}\text { Lesson Plans and data on impact } \\
\text { to classroom and students were } \\
\text { collected via post-training } \\
\text { surveys and the LMS. }\end{array}$ \\
\hline $\begin{array}{l}\text { Foster K-12 student } \\
\text { exposure and interest in } \\
\text { STEM by reaching over } \\
\text { 1000 students at } \\
\text { secondary school levels }\end{array}$ & $\begin{array}{l}\text { Teach and Develop 5E Lesson } \\
\text { Plans designed and taught by } \\
\text { participant/teachers. }\end{array}$ & $\begin{array}{l}\text { Survey data from teachers } \\
\text { indicated that over 3000 students } \\
\text { were reached. }\end{array}$ \\
$\begin{array}{l}\text { Development of a circulating } \\
\text { curriculum kit continues to be } \\
\text { distributed to interested middle } \\
\text { school teachers state-wide. }\end{array}$ & $\begin{array}{l}\text { Production of Green Box } \\
\text { (circulating curriculum kit) } \\
\text { using lesson plans generated by } \\
\text { teacher-participants. }\end{array}$ \\
\hline
\end{tabular}

Although 30 people initially signed up for this professional development experience, 26 completed both pre- and post- surveys.

Those completing all aspects of the training were all in-service teachers, including 12 men and 14 women working at the middle- or high school level. Subjects taught by these teachers included computer science, robotics, math, chemistry, physical science, biology, electronic technology, forensic science, and one instructor who was a special educator supporting students in math and science at the high school level. Fifty eight percent of the participating teachers held a Master's degree, and over $70 \%$ of the participants had four or more years' teaching experience. Sixty five percent of the teachers applying to take part in 
the project stated "an interest in incorporating UAS into pre-existing STEM curriculum. The second most popular response (selected by $24 \%$ of participants) was the goal to include UAS as part of an advanced studies course in Career and Technical Education (CTE).

As noted in Brooks and Gibson (2012), the use of hybrid approaches is in keeping with contemporary ways of learning and served to boost the efficiency and reach of professional development experiences. The authors state, "The catalyst for the transformation of education, as envisioned by countless educational leaders, may lie in reimaging professional development as professional learning in a networked age"

This project sought to apply blended or hybrid approaches to optimize opportunities for teachers, limit the need to travel, and boost productive outcomes.

Components of the project included:

- Access to an online course site with discussion forums, content, preworkshop quiz/assessment, and webinar platform;

- Participation in a dinner reception and keynote address that included access to explore a drone collection hosted at DRI;

- Training and hands-on experiences with (1) flight simulation software (2) programming and flying of programmable drones, and (3) guided use of small UAS during the workshop hosted at Nevada State College

- Support and training in the design of lesson plans relating to UAS in STEM;

- Opportunities to compete in a lesson plan contest resulting in awards that included recognition such as plaques, inclusion of work in the circulating curriculum kit. The teacher designing the top ranked lesson plan (based on a rubric developed by the project team) received a field trip during which her classroom of secondary STEM students spent the day learning about (and using) UAS and making use of flight simulation software, and

- A Green Box circulating curriculum kit available to middle school STEM teachers. The kit included a drone, instructions, and needed materials for lesson plan implementation.

Data collection tools included the initial teacher-survey at point of application, data generated by the online learning management system, test score data (based on online completion of a UAS safety and ethics quiz), attendance at live trainings and events, number of teachers participating in the lesson plan competition, and data from a follow-up survey.

The pre- post- data collected first at point-of-application and later after the project's conclusion allowed the PIs to measure change based on a scale that was self-reported by the teachers themselves. Measured on a 1-5 scale (5 being confident) the Likert scale included questions on teacher access to UAS in the classroom and teacher experience using UAS in the classroom. Additionally, the 
follow up survey sought to solicit specific observations and comments relating to the number of students who benefited from the teacher-participation in the training and (where applicable) student responses to the use of UAS in the classroom.

By effectively preparing these 26 public school teachers, the project developed STEM teacher capacity via innovative UAS curriculum that had the estimated near-term impact of directly reaching over a thousand secondary students taught by those teachers.

Based on actual reported data from the follow up survey, the reach of this project benefited over 3,000 students, including those in after school clubs as well as in the context of the classroom.

\section{Results}

The research confirmed that the UAS online course and associated workshops and demonstrations helped address the training barrier. It led to higher levels of UAS availability and increased usage of UAS in the STEM curriculum among the 26 teachers who took part in the training. Based on teacher reports, findings suggest the viability and value of preparing teachers to incorporate UAS in the teaching of various STEM subjects. Collection of data relating to the number of students taught was based on teacher-report. In fact, responses to the follow-up survey question inquiring about the number of students reached through the lessons, considerably more than the 1000 students estimated were actually reached. Participating teachers also reported a high level of engagement on the part of the middle and high school students who took part in the resulting lessons in a variety of STEM fields.

Regarding the outreach provided by the circulating curriculum kit, the organization managing the kit noted that the lesson plans generated were of high quality but that challenges (such as the need for closer NGSS alignment) represented a barrier to teacher-implementation of the kit. As a result, the content of the original curriculum kits is now being reworked into "STEM kits" for use in informal educational settings such as after school clubs, scouts, and CTE programs starting in summer 2020.

In addition to having a substantial impact in terms of the number of students reached, the project design allowed the organizers to provide the teacherparticipants with important safety and privacy information before they ever came on campus for the hands-on training. A required prerequisite to the faceto-face training was an online UAS quiz on privacy and safety guidelines. Although multiple quiz attempts were allowed, 27 of the workshop participants persevered to receive a perfect score of 10/10. Twenty-six teacher-participants later attended the face-to-face training and completed the follow up survey, and fifteen of those participated in a UAS lesson plan competition and received Continuing Education credits for their time and effort. Those who opted not to submit lesson plans listed time limitations as the primary reason for not completing that aspect of the project. Lesson plans that were generated from this 
effort were expertly edited and formatted by the project team, and are publicly available at https://www.smore.com/uycek.

Based on the data from the pre and post surveys, teacher-access to drones increased considerably, from $26.4 \%(n=34)$ at point of workshop registration to $46.2 \%(\mathrm{n}=26)$ after the training.

With its multi-faceted design, the training also led to higher levels of implementation in the classroom. While $17.6 \%(n=34)$ during the pre-workshop survey stated they had used a drone in their classroom, the post-survey results showed a significant increase with $34.6 \%(n=26)$ stating they had used a drone as part of their classroom instruction.

The project led to greater levels of experience and self-efficacy using UAS among the participating teachers. The survey asked the teachers about experience level with UAS. It used a scale of 1-5, with 1 being no experience, 3 being some experience, and 5 being experienced. Although the initial response to this question revealed that only three people had a level 3 or higher, the post program survey demonstrated that 13 people had increased their experience to 3 or more.

The 26 teachers responding to the post-project survey were satisfied or very satisfied with the overall professional development experience. This was based on a 1-5 point rating scale, with 5 being 'very satisfied'. Figure 2 depicts that data.

\section{Teacher-Participant Satisfaction with the Overall Training Experience}

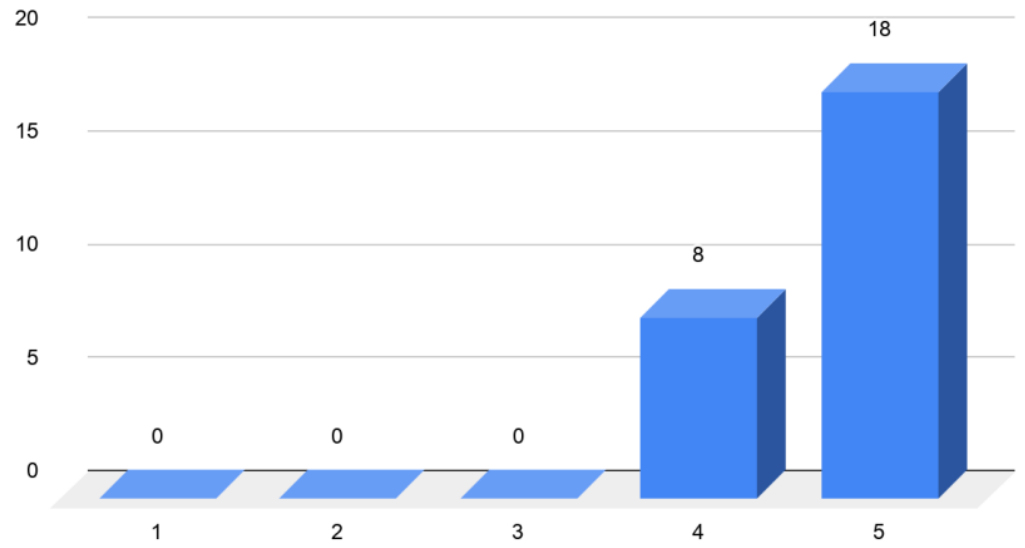

Figure 2: The professional development experience was highly rated by participants.

Adding further to the collection of resources to perpetuate benefits of this project, 14 teacher-created lesson plans were produced, with four being included in curriculum kits for state-wide distribution. In response to the project's lesson plan competition, several participating teachers teamed up on the creation of lesson plans, which were submitted for competitive evaluation by the project team. The lesson planning process began during the actual face-to-face workshop, with the finished lesson plans submitted ten days later via the online 
learning management system. Prizes involved recognition of teacheraccomplishments, dissemination of teacher-created lesson plans, and an allexpense paid field trip that brought a class of 18 AP biology high school students to participate in a day-long training associated with UAS in STEM. Teachers suggested that the training would have benefitted through the inclusion of another day for additional hands-on use of drones and for more time in the collaborative creation of lesson plans.

In addition to providing teaching with training that will help them implement innovative lessons on an ongoing basis, the sharing of edited lesson plans was accomplished through conference presentations, NASA press releases, and online publication via the PIs' project website. Additionally, the Green Box curriculum kit is still in high demand by teachers and schools.

This NV NASA project had ambitious goals in terms of providing foundational information, hands-on skills, support for lesson plan generation and classroom implementation, as well as outreach to teachers beyond the scope of the original participants. Based on the successes derived from this project, future professional developers should consider the use of a hybrid design, involving online instruction and testing, webinars, keynotes, hands-on activities, and lesson plans and curriculum kit distribution.

Based on the post-project survey that was distributed approximately one month after the face-to-face training events, collective reports from the 26 participating teachers indicated that over 3,000 students benefited through teacher implementation of lessons learned and implemented based on this training.

\section{Conclusion}

The project easily exceeded initial goals of reaching 1000 students through the inclusion of UAS in the STEM curriculum. Teachers were able to incorporate UAS in the creation of viable lesson plans on a number of STEM topics and they increased their access and their practical use of UAS in the classroom. The multifaceted and hybrid design was key to the implementation and success of this professional development project.

Within parameters of limited time, money, and the relatively low number of teacher participants, the project was effective, with teachers reporting high levels of student engagement and benefits to over 3000 students. The high level of productivity for a professional development project of this size may be attributed in part to the use of a blended instructional design. Additionally, the circulating curriculum kit had a positive impact on hundreds of students whose teachers were not directly involved in the face-to-face training. Future projects involving the incorporation of complex elements or technologies may gain efficiency and effectiveness by adopting aspects of this professional development project design.

This project made use of a hybrid multi-phase design to support secondary STEM teachers seeking to enhance their curriculum through a focus on how a 
specific technology (UAS) can promote student engagement and interest in STEM. Due to the limited time for face-to-face training, this project implemented and established the value of a blended and multi-faceted instructional design to make the most of teacher/participant time and project resources.

Suggested areas for future research include project/interventions that implement and measure a blended and multi-phase instructional design to provide professional development for teachers seeking to incorporate technologies such as robotics, UAS, and mobile application design in the general and/or special education curriculum.

\section{References}

Adams, B. S., Cummins, M., Davis, A., Freeman, A., Hall, G. C., \& Ananthanarayanan, V. (2017). NMC Horizon Report: 2017 Higher Education Edition. Austin, Texas: The New Media Consortium

Brooks, G. \& Gibson, S. (2012). Professional learning in a digital age. Canadian Journal of Learning and Technology, 38(2), 1-17. doi:10.4324/9781315853529

Boitshwarelo, B. (2009). Exploring blended learning for science teacher professional development in an African context. International Review of Research in Open and Distance Learning, 10(4), 1-19. doi:10.19173/irrodl.v10i4.687

Bryans-Bongey, S. (2018). Encouraging student engagement in STEM fields through teacher training and the use of unmanned aircraft systems (UAS). In W. James \& C. Cobanoglu (Eds.), Advances in Global Education and Research (Ch. 17). Sarasota, FL: ANAHEI Publishing. Published online at https:/ / scholarcommons.usf.edu/cgi/viewcontent.cgi?cv=1\&amp $=\& a r t i c l e=10$ $17 \&$ context=anaheipublishing

Committee on Highly Successful Schools or Programs for K-12 STEM Education, Board on Science Education, Board on Testing and Assessment, Division of Behavioral and Social Sciences and Education, and National Research Council. (2011). Successful K-12 STEM: Identifying effective approaches in science, technology, engineering, and mathematics. Retrieved from http://www.nap.edu/catalog.php?record_id=13158. doi:10.17226/13158

Carnahan, C, Crowley, K., Hummel, L, \& Sheehy, L. (2016). New perspectives on education: Drones in the classroom. Proceedings of the Society for Instructional Technology in Education, (pp. 1920-1924).

Creswell, J. W. (2013). Research design: Qualitative, quantitative, and mixed methods approaches (4th ed.). Thousand Oaks, CA: Sage.

Desert Research Institute. (2016). DRI GreenPower: Green box program. Retrieved from http://greenpower.dri.edu/green-box-program

Federal Aviation Administration. (2019). Getting started: The new small UAS rule. Retrieved from http://www.faa.gov/uas/getting_started/

Fishman, B., Konstantopoulos, S., Kubitskey, B. W., Vath, R., Park, G., Johnson, H., \& Edelson, D. C. (2013). Comparing the impact of online and face-to-face professional development in the context of curriculum implementation. Journal of Teacher Education., 64(5), 426. doi:10.1177/0022487113494413

Fokides, E., Papadakis, D., \& Kourtis-Kazoullis, V. (2017). To drone or not to drone? Results of a pilot study in primary school settings. Journal of Computers in Education, 4(3), 339-353. doi:10.1007/s40692-017-0087-4

Kehoe, T., Schofield, P., Branigan, E., \& Wilmore, M. (2018). The double flip: Applying a flipped learning approach to teach the teacher and improve student satisfaction, Journal of University Teaching \& Learning Practice, 15(1), 1-14. 
Kuhlenschmidt, S. (2010). Issues in technology and faculty development. In K. H., \& Douglas L. Robertson \& Associates (Eds.) A guide to faculty development (pp. 259276). San Francisco: Jossey-Bass.

Levy, L. (2015, October). What drone technology can teach students. Retrieved from http://www.edudemic.com/drones-classroom-can-happen/

Moore, T., \& Smith, K. (2014). Advancing the state of the art of STEM integration. Journal of STEM Education, 15(1), 5-10.

National Aeronautics and Space Administration. (2016). NASA strategic plan - 2014. Retrieved from https://www.nasa.gov/sites/default/files/files/FY2014_NASA_SP_508c.pdf

Nevada Governor's Office of Economic Development. (2012). Moving Nevada forward: A plan for excellence in economic development. Retrieved from http://www.diversifynevada.com/uploads/studies/2012_NVGOED_StatePlan _Full.pdf

Nevada System of Higher Education (NSHE). (2015). Nevada science and technology plan. Retrieved from http://system.nevada.edu/tasks/sites/Nshe/assets/File/BoardOfRegents/Ag endas/2015/jun-mtgs/arsa-refs/ARSA-11.pdf

Smith, P., Sefton, V., \& Chaffer, L. (2015). Drones: ICT in action. Geography Bulletin, 47(2), 25-34.

Wiggins, G. P., \& McTighe, J. (2008). Understanding by design. Alexandria, Va: Association for Supervision and Curriculum Development.

World Economic Forum. (2016). The future of jobs: Employment, skills and workforce strategy for the fourth industrial revolution. Retrieved from http://www3.weforum.org/docs/WEF_Future_of_Jobs.pdf

\section{Acknowledgment}

This material is based upon work supported by the National Aeronautics and Space Administration (NASA) under Grant Contract Agreement No. NNX15AI02H. 